\title{
Endometriose
}

\section{by Tampon Gebruikers}

$L$ Roets

Ph D

Skool vir Verpleegkunde

Universiteit van die Oranje-Vrystaat

\&

\section{O van Rijswijck}

B.Soc.Sc.

Universiteit van die Oranje-Vrystaat

\section{OPSOMMING}

Endometriose word as een van die moontlike oorsake van infertiliteit beskou. Of endometriose by tampon gebruikers meer dikwels as by nie-tampon gebruikers voorkom, is dus vir die moderne vrou asook vir verpleegkundiges ' $n$ belangrike punt van bespreking

Tampon gebruik kan met ' $n$ verhoogde insidensie van endometriose in verband gebring word. Dit blyk dat ' $n$ voorligtingsprogram, deur primêre gesondheidsorg verpleegkundiges, oor die potensiële gevaar van tampon gebruik, die insidensie van endometriose noodwendig sal verlaag, infertiliteits problematiek sal verminder en optimale vroulike gesondheidsorg sal verseker.

\section{INLEIDING EN \\ PROBLEEMSTELLING}

Endometriose is die aanwesigheid en abnormale groei van endometriële weefsel ekstern tot die uterus, wat dan siklies op ovariële hormoonstimulasie reageer (Brink, 1992:124).

Alhoewel die toestand die afgelope jare baie aandag verkry het, is endometriose en presies wat dit veroorsaak steeds ' $n$ raaisel. Ten spyte van verskeie teorië is daar nog geen enkele oorsaak geidentifiseer nie en word daar na ' $n$ aantal verskillende teorië verwys (Biley, 1995:33; Jones, Wentz \& Burnett, 1988). Die teorie wat meer algemeen aanvaar word en deur verskeie navorsers onderskryf word, is dié deur Sampson. Volgens Sampson se teorie van retrograde menstruasie mag endometriële weefsel tydens menstruasie, as gevolg van terugwaartse vloei deur die Fallopiaanse buise, in die peritoneale holte beland en aan die peritoneum vasheg en groei. Die risiko vir 'n menstruele refleks verhoog as menstruele vloei deur ' $n$ uteriene of servikale obstruksie soos vaginale tamponne of koïtus met orgasme,

\section{SUMMARY: Endomitriosis}

\section{among tampon users}

Endometriosis has been recognized as one of the possible causes for infertility. If endometriosis occurs more often in a women who uses tampons comparing to those who do not, it is an important point of discussion to the modern women and nurses.

Resent research (van Rijswijck \& Botha, 1997 ) indicated that a correlation between the use of tampons during menstruation and endometriosis exists. It seems that an educational program, by primary health care workers, indicating the potential dangerous effects of tampon use will lower the incidence of endometriosis, thus the problems with infertility could lesson and optimal health care to women could be improved.

geïnhibeer word (Wedell, Bellings \& Fayez, 1985:280). Vrouens met kort siklusse ( $<28$ dae) en swaar menstruele vloei wat beide sanitêre doekies en tamponne vereis, wat vry dreinasie belemmer, het 'n groter predisposisie vir ' $n$ menstruele refleks (Llewellyn-Jones, 1994:261).

Die patogenese van endometriose is dus steeds onseker, maar die teorie van retograde menstruasie geniet al hoe meer aandag (Jurgensen, Mettler, Volkov \& Parwaresch, 1996:369). Endometriose mag dus ' $n$ uitvloeisel van hierdie teorie wees en tampongebruik mag met endometriose in verband gebring word.

Navorsers beweer dat 30 tot $40 \%$ van vrouens met endometriose, probleme met konsepsie ervaar (Biley, 1995:34), terwyl soveel as $93 \%$ van vrouens wat vir infertiliteitsondersoeke gaan met endometriose gediagnoseer word (Martin, 1995:2).

Dit is dus nodig om te bepaal of daar ' $n$ direkte verband tussen die insidensie van endometriose en die gebruik van 


\section{DOELSTELLING}

Die doel van die studie was om die insidensie van endometriose by tamponen by nie-tampon gebruikers by ' $n$ infertiliteitskliniek vas te stel.

Dit was nie die doel om oorsaaklikheid te bewys nie, maar eerder om te beskryf en te verken en sodoende die verhouding tussen die veranderlikes, naamlik endometriose en tampon gebruik, aan die hand van statistiese analise van data te bepaal. So kon die data, wat teenstrydig met vorige skynbaar geldige opvattings is, deur van beskrywende en verkennende navorsing gebruik te maak, gedokumenteer word (Neuman, 1997:20). Die navorsers wil dus deur die studie, die gedokumenteerde veiligheid van tampon gebruik bevraagteken.

\section{METODOLOGIE}

Hierdie studie was op die verkryging van insig en die verwerwing van begrip ten opsigte van die insidensie van endometriose by tampon- en nie-tampon gebruikers gerig.

Die navorsing was nie-eksperimenteel van aard, aangesien daar geen manipulasie van veranderlikes of kontrolegroepe was nie. Die aard van die eksperimentele subjekte, naamlik pasiënte vanaf die infertiliteitskliniek in Bloemfontein, het dit eties ongewens gemaak om eksperimentele of kwasieksperimentele studies uit te voer (Uys \& Basson, 1991:48-49). In die betrokke studie, is data slegs vanaf pasiëntrekords verkry en was daar geen kontak met werklike navorsingsubjekte nie (Hogstel \& Sayner, 1986:84).

\section{EIIESE ASPEKTE}

Dit is voldoende om ' $n$ organisasie of instansie se toestemming te bekom indien pasiëntrekords vir die navorsing benodig word (Uys \& Basson, 1991:108). Hiervoor is geskrewe toestemming van die infertiliteitskliniek verkry. Om die potensiële navorsingsubjekte, binne die gesondheidsorgmilieu, te beskerm (Cormack, 1991:37-38) is die navorsingsprotokol aan die Etiekkomitee van die Fakulteit van Gesondheidswetenskappe (OVS) vir goedkeuring voorgelê, waarna toestemming vir die uitvoering van die navorsing verkry is. Aangesien privaatheid ' $n$ mensereg is, wat ook deur die konstitusie beskerm word (Neuman, 1997:452) het die navorsers aan die etiese aspek van privaatheid voldoen. Slegs data wat noodsaaklik vir die doeleindes van die studie was, naamlik die diagnose, ouderdom, tampon- en nie-tampon gebruik is vanuit die lêers verkry. Geen identifiserende of vertroulike inligting kan aan die data gekoppel word nie en anonimiteit is dus beskerm.

\section{SIEEKPROEF}

' $n$ Gerieflikheidseleksie is as steekproefmetode vir die studie gekies, aangesien al die elemente binne die populasie nie ' $n$ ewekansige geleentheid om in die steekproef ingesluit te word, gehad het nie (Mouton, 1996:235; Hulley \& Cummings, 1988:25). Die populasie was die pasiënte wat huidiglik of onlangs (1995-1997) by ' $n$ infertiliteitskliniek in Bloemfontein, infertiliteitsbehandeling ontvang het en die steekproef is as volg uit laasgenoemde populasie getrek.

Twee honderd pasiënt lêers is terugwerkend vanaf die nuutste dokument getrek, totdat daar op doelbewuste wyse aan die steekproefgrootte voldoen is, naamlik 100 pasiënt lêers waarop ' $n$ diagnose van endometriose en ' $n$ verdere 100 lêers waarop diverse toestande as diagnose aangedui is. Die grootte van die steekproef is op aanbeveling van die biostatistiekdiens van die Universiteit van die OranjeVrystaat gedoen nadat alle statistieke rakende die getal pasiënte by die infertiliteitskliniek aan hulle bekend gemaak is.

Die volgende insluitingskriteria vir die steekproef moes geld:

* Die infertiliteits geassosieerde diagnose op die rekords, moes ' $n$ vroulike oorsprong hê (dus is rekords met manlike oorsake van infertiliteit nie vir insluiting oorweeg nie, ongeag of die eggenote aan die ander kriteria voldoen het of nie);

* die diagnose van endometriose moes laparoskopies bevestig gewees het;

* die keuse van sanitêre higiëne tydens menstruasie, moes duidelik gespesifiseer gewees het, naamlik of tampon gebruik of sanitêre doekies. Pasiënte wat ' $n$ kombinasie van metodes gebruik, is as tampon gebruikers geag; en

* pasiënte se ouderdomme moes genoteer wees. Alle pasiënte ouer as 16 jaar is in drie ouderdomskategorieë, naamlik 16-25 jaar, 26-34 jaar en ouer as 35 jaar, verdeel.

\section{DATA-INSAMELING EN - INSTRUMENT}

Vanuit bestaande pasiëntrekords in die infertiliteitskliniek is data in verband met ouderdom, diagnose (endometriose of diverse diagnoses) en die gebruik van tamponne al dan nie, verkry. 'n
Steekproef grootte van 100 endometriose lyers en ' $n$ verdere 100 pasiënte met diverse toestande is verkry. Die 100 endometriose lyers is daarna in tampon en nie-tampon gebruikers verdeel, terwyl dieselfde met pasiënte met diverse toestande gedoen is. in beide kategorieë is die ouderdomme van die pasiënte aangeteken

Die data-insameling het aan die hand van ' $n$ kontrolelys geskied. Die volgende veranderlikes, naamlik diagnose, ouderdom en die keuse van sanitêre higiëniese gebruik, is gespesifiseer. Die veranderlikes is om die volgende redes ingesluit:

Diagnose: Drie ouderdomskategorieë is onderskei, naamlik16-25 jaar, 26-34 jaar en ouer as 35 jaar. Dames ouer as 16 jaar verteenwoordig vrouens in hul reproduktiewe jare, wat dus ook die risiko loop om infertiliteitsprobleme en dus moontlik endometriose te ervaar.

Tampon gebruik: Hul veranderlike is slegs in " $n$ "ja" of "nee" kategorie verdeel. Dames wat ' $n$ kombinasie van tamponne en doekies gebruik, is as tampon gebruikers gereken, aangesien daar wel 'n verhoogde risiko vir ' $n$ retrograde refluks volgens Sampson se teorie bestaan (Jones, Wentz \& Burnett, 1988:304).

Hierdie drie veranderlikes is onderskeidelik op nominale (diagnose en tampon gebruik) en ordinale vlak (ouderdom) van meting geoperasionaliseer. Die eenvoudigste vlak van meting is nominaal, wat op ' $n$ verskil in kategorie dui. Ordinale vlak van meting dui op verskillende kategorieë van ' $n$ spesifieke veranderlike, wat gerangskik of georden kan word (Neuman, 1997:147; Reid \& Boore, 1987:49).

Die data-analisering van kwantitatiewe navorsing, word gewoonlik deur middel van statistiese analise rekenaar-programme, gedoen (Burns \& Grove, 1993:605; Brink, 1994:15). Vir die studie, is die SPSS-rekenaarprogram (Statistical package for the Social Sciences) gebruik. Hierdie program vereis dat numeriese waardes aan veranderlikes toegeken word, waarna dit direk vir verdere analise ingevoer word (Bausell, 1986:230). Beide enkelveranderlike- en bivariate veranderlike analises is tydens die dataverwerking gedoen.

Alhoewel die mate van kontrole oor die spesifieke data-insamelingsmetode. beperk is (Mouton,1996:144) is die reaktiwiteit van die data-kategorieë verlaag en was daar nie bedreiging vir die geldigheid van die bevindinge nie. Hierdie data-insamelingsmetode het ook die voordeel van koste-effektiwiteit, eenvoud en objektiwiteit ingehou, aangesien variasie met pasiëntkontrak 
uitgeskakel is.

Die betroubaarheid van die datainsamelingsinstrument is verhoog deur die absolute kategorieë wat gestel is. Die vrae is slegs met 'n "ja" of "nee" vanuit reeds gedokumenteerde data gekategoriseer. Daar was dus geen ruimte vir subjektiwiteit of variasie in die navorser interpretasie gelaat nie (Burns \& Grove, 1993:339). Deurlopende kruiskorrelasie tussen die navorsers het die betroubaarheid ook verder verhoog (Mouton, 1996:44).

Die geldigheid van die instrument ten opsigte van diagnostiese kategorieë is verhoog, deurdat die diagnose van endometriose ' $n$ klinies bepaalde toestand, wat laparoskopies bevestig is, is (Jurgensen et al., 1996:370). Daar was dus geen risiko vir die waninterpretasie van data nie.

\section{NAVORSINGSBEVINDINGE}

Endometriose word nie voor menarg gediagnoseer nie, aangesien die toestand van hormonale stimulasie (esterogeen), vir groei en verspreiding, afhanklik is. Endometriose kan dus al tydens die laat tienerjare by meisies, met klagtes van chroniese abdominale pyn, laparoskopies gediagnoseer word (Garner \& Webster, 1985:10s).

Die ouderdomsamestelling van die steekproef was:

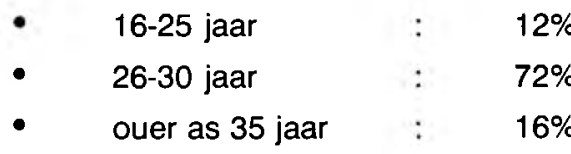

Die $12 \%$ van pasiënte tussen 16 en 25 jaar kan verklaar word aan die hand van paartjies wat die huwelik uitstel en gevolglik later met ' $n$ gesin wil begin (Gerdes, 1988:236). Infertiliteitsprobleme word dus hoofsaaklik eers in die vrou se middel tot laat twintigerjare ontdek (Wedell et al., 1985:280). Dit word in die $72 \%$ van die pasiënte wat in die tweede kategorie van ouderdomsamestelling (26-34 jaar) gegroepeer is, weerspieël. Hierna neem fertiliteit af onder andere as gevolg van natuurlike verouderingsprosesse en tradisioneel reeds gevestigde gesinne (Gerdes, 1988:352).

Uit die totale groep van 200 respondente was $41 \%$ tampon gebruikers en $59 \%$ het van alternatiewe metodes gebruik gemaak. Volgens Sampson se teorie van retrograde refluks het $41 \%$ van subjekte dus meer as ' $n$ normale refluks. Die vrag was egter hoe hierdie keuse met diagnostiese kategorieë sou korreleer. Van die 100 respondente wat endometriose het en infertiliteitsbehandeling ontvang, gebruik $63 \%$ tamponne, terwyl die oorblywende $37 \%$ van alternatiewe metodes van sanitêre

Figuur 1 : Sanitêre higiëne by endometriose gediagnoseerde pasiënte

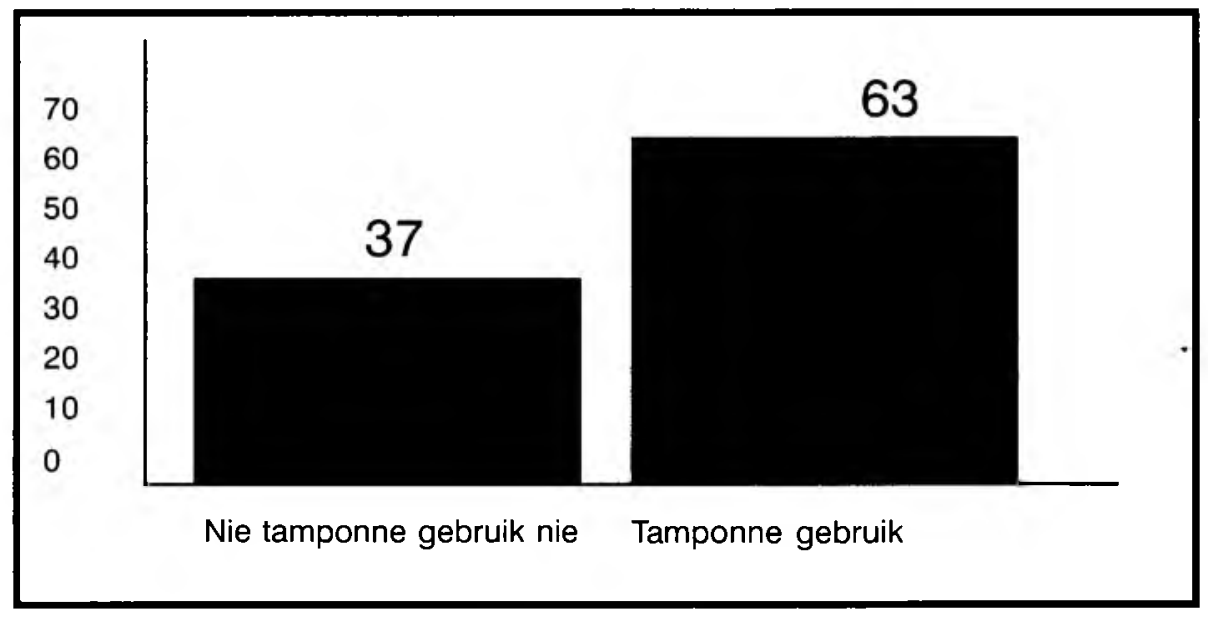

higiëne tydens menstruasie gebruik maak. Die meerderheid (63\%) van endometriose lyers het dus ' $n$ verhoogde retrograde refluks as gevolg van vaginale obstruksie deur tampon gebruik. In slegs $37 \%$ van endometriose lyers was daar vry dreinasie van menstruele vog (kyk Figuur 1).

In teenstelling met bogenoemde resultate was respondente in die "ander" diagnostiese kategorie slegs in $18 \%$ van gevalle tampon gebruikers gewees, met die oorblywende $82 \%$ respondente wat van diverse metodes van sanitêre higiëne gebruik gemaak het (kyk Figuur 2).

Dit het dus voorgekom dat tampon gebruik nie met die insidensie van diverse diagnoses korreleer nie. Daar is egter ' $n$ beduidende verband van endometriose met tampon gebruik, wat in die lig van die refluksteorie die insidensie van endometriose sal verhoog.

\section{GEVOLGTREKKINGS}

Tydens die data-insameling, wat aan die hand van ' $\mathrm{n}$ kontrolelys uitgevoer is, is infertiliteitsdiagnoses soos anovulasie, bekkenverklewings en buispatologie as "ander" diagnoses by die diagnostiese kategorie geklassifiseer. Die patofisiologiese aspekte van endometriose wat tot infertiliteit aanleiding gee, is egter ook onder andere bekkenverklewings, anovulasie en buisfaktore, soos ingekorte buisoptelmeganisme (Jones et al., 1988:306; Wessels \& Lindeque, 1989[1]:19; Wessels, 1994:205-206).

Aangesien al die pasiënte nie noodwendig laparoskopieë as diagnostiese ingreep gehad het nie of waar laparoskopieë wel uitgevoer is en die kliniese sigbare patologie as diagnose aanvaar is, is dit wel moontlik dat hierdie "diagnoses" deel van die manifesterende patologie van endometriose kon gewees het. Dit impliseer dus ' $n$ hoër as gedokumenteerde insidensie van endometriose. Uit die navorsingsresultate is dit ook duidelik dat tampon gebruik as bydraende faktor tot endometriose, realisties in diagnosering gebruik kan word.

'n Gestandaardiseerde klassifikasie-

\section{Figuur 2 : Sanitêre higiëne by pasiënte met ander diagnoses}

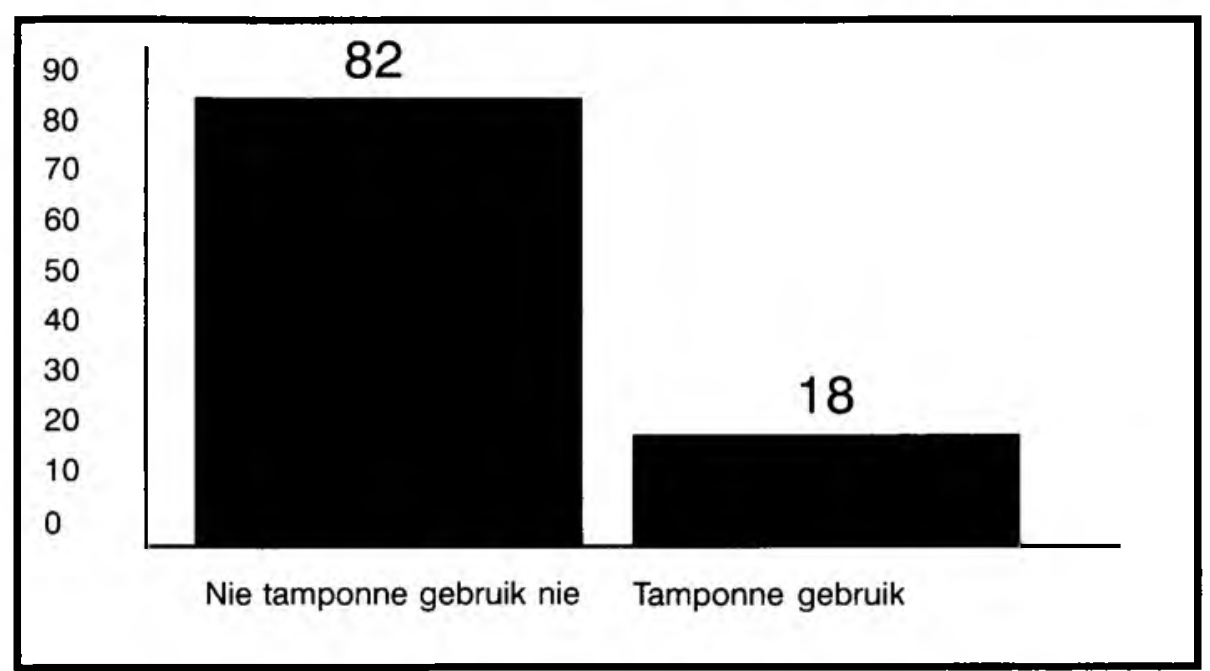


stelsel, met omvattende kriteria, wat tampon gebruik kan insluit, sou die konsekwente diagnose van endometriose verseker en oorvleueling en waninterpretsie van kliniese manifestasies voorkom.

Geen behandelingsmodaliteit is nog as meer effektief, as ' $n$ ander vir endometriose bewys nie (Martin, 1995 :2). Derhalwe is dit ' $n$ kontroversiële besprekingspunt, wat dit noodsaak dat verpleegkundiges en geneeshere op hoogte van die nuutste verwikkelinge moet bly, ten einde optimale sorg en hantering van die pasiënt met endometriose te verseker.

Dit is ook waar dat tampon gebruik deel van die moderne vrou se lewensstyl geword het en dat daar positief oor die gemak, gerief en onopsigtelikheid daarvan, geredeneer kan word. Gegewe die hoër insidensie van endometriose by die tampon gebruiker en die verband van endometriose met infertiliteit is ' $n$ doelgerigte voorkomingsprogram binne ' $n$ atmosfeer van respek en vertroue egter noodsaaklik.

Hier word weereens die belangrike rol wat die primêre gesondheidsorg verpleegkundige, ten opsigte van voorligting oor tampon gebruik speel, ten einde so ' $n$ bydrae tot die voorkoming van endometriose te maak, beklemtoon.

' $n$ Gesinsbeplanningskliniek is die ideale milieu om ' $n$ groot deel van die teikengroep, naamlik vroue wat menarg bereik het, te betrek. Die primêre gesondheidsorg verpleegkundige is in die unieke posisie om hierdie opvoedingsrol te vertolk. Dit sou egter ook sinvol kon wees om bogenoemde program as deel van weerbaarheids opvoeding in skole aan te bied.

\section{SAMEVAITING}

Almal binne die gesondheidsorgmilieu, hetsy die geregistreerde verpleegkundige of gemeenskapwerker, asook die moeder van ' $n$ tiener dogter, het ' $n$ baie belangrike rol, om ten opsigte van voorligting te vervul. Endometriose is ' $n$ ginekologiese toestand waarvan die insidensie verminder kan word. Daarom is dit noodsaaklik dat voorligting vroegtydig aan dames, wat tamponne wil of alreeds gebruik, verskaf word, aangaande die potensiële bydraende faktor van tampon gebruik tot die verhoogde insidensie van endometriose en die verband van endometriose met infertiliteit. Indien ' $n$ voorligtingsprogram aangaande tampon gebruik suksesvol toegepas kan word, sál die voorkoms van endometriose noodwendig verlaag, infertiliteitsprobleme verminder en optimale vroulike reproduktiewe gesondheidsorg verseker word.

\section{BIBLIOGRAFIE}

BAUSELL, R.B. 1986. A practical guide to conducting empirical research. Harper \& Row Publishers: New York.

BILLEY, A. 1995. Making sense of ... diagnosing and treating endometriosis. Nursing Times, 91(9):33-34.

BRINK, A.J. 1992. Woordeboek van Afrikaanse Geneeskunde Terme. Nasau Beperk: Universiteit van Stellenbosch.

BRINK, H. 1994. Basic issues in clinical nursing research. Nursing RSA, 9(8):14-16.

BURNS, N. \& GROVE, S.K. 1993. The practice of nursing research/conduct, critique and utilization. Philadelphia: W.B. Saunders Co.

CORMACK, D.F.S. 1991. The research process in nursing. London: Blackwell Scientific Publications.

GARNER, C.H. \& WEBSTER, B.W. 1985. Endometriosis, Journal of Obstetric, Gynecologic and Neonatal Nursing: Infertility/Fertility Supplement, 14(6):10s-19s.

GERDES, L.C. 1988. Die ontwikkelende volwassene. Durban: Butterworts.

HULLEY, S.B. \& CUMMINGS, S.R. 1988. Designing clinical research: An epidemiologic approach. Baltimore: Williams \& Wilkins.

JONES, H.W., WENTZ, A.C. \& BURNETT, L.S. 1988. Novak's textbook of gynecology. Nashville: Williams \& Wilkins.

JüRGENSEN, A., METTLER, L., VOLKOV, N.I. \& PARWARESCH, R. 1996. Proliferative activity of the endometrium throughout the menstrual cycle in infertile women with and without endometriosis. Fertility and Sterility, 66(3):369-374.

LIEWELLYN-JONES, D. 1994. Fundamentals of obstetrics and gynaecology. London: Mosby.

MARTIN, D.C. 1995. Pain and infertility - a rationale for different treatment approaches. British Journal of Obstetrics and Gynaecology, 102(12):2-3.

MOUTON, J. 1996. Understanding social research. Pretoria: J.L. van Schaick Publishers.

NEUMAN, W.L. 1997. Social research methods: Qualitative and quantitative approaches. Needham Heights: Allyn \& Bacon.

REID, N.G. \& BOORE, R.P. 1987. Research methods and statistics in health care London: British Library Cataloguing in Publication Data.

UYS, H.M.M. \& BASSON, A.A. 1991. Navorsingsmetodologie in die Verpleegkunde. Pretoria: HAUM-tersier.

WEDELL, M.A., BILLINGS, P. \& FAYEZ, J.A. 1985. Endometriosis and the infertile patient. Journal of Obstetric, Gynecologic and Neonatal Nursing, 14(4):280-283.

WESSELS, P.H. \& LINDEQUE, H.W. 1989. Endometriose: 'n Oorsig van die etiologie en patogenese. Geneeskunde, 31(6):16-21.

WESSELS, P.H. 1994. Endometriosis. Topics in Obstetrics \& Gynaecology, 203-209 